\title{
XXIX. On the phœnomena of thin plates of solid and fluid substances exposed to polarized light
}

\author{
Sir David Brewster K.H. D.C.L. F.R.S. V.P.R.S. Edin.
}

To cite this article: Sir David Brewster K.H. D.C.L. F.R.S. V.P.R.S. Edin. (1848) XXIX. On the phœnomena of thin plates of solid and fluid substances exposed to polarized light, Philosophical Magazine Series 3, 32:214, 181-199, DOI: 10.1080/14786444808645962

To link to this article: http://dx.doi.org/10.1080/14786444808645962

册 Published online: 30 Apr 2009.

Submit your article to this journal $\lceil\pi$

Џ Article views: 3

Q View related articles $₫$ 
XXIX. On the Plcenomena of Thin Plates of Solid and Fluid Substances exposed to Polarized Light. By Sir Divid Brewster, K.H., D.C.L., F.R.S., and V.P.R.S. Edin.*

[With a Plate.]

HAVING received from Dr. Joseph Reade one of his 11 beautiful instruments called the Iriscope, and made several experiments with it, I soon perceived that it might be advantageously employed in various investigations in physical optics. This instrument consists mainly of a plate of highly polished black glass, having its surface smeared with a solution of fine soap, and subsequently dried by rubbing it clean with a piece of chamois leather. If we breathe upon the glass surface, thus prepared, through a glass tube, the vapour is deposited in brilliant coloured rings, the outermost of which is black, while the innermost has various colours, or no colour at all, in proportion to the quantity of vapour deposited. The colours in these rings, when seen by common light, correspond with Newton's reflected rings, or those which have black centres, the only difference being, that in the plate of vapour, which is thickest in the middle, the rings in the iriscope have black circumferencest. By using a large system of rings, or depositing the vapour in straight lines in the plane of incidence, we can at once observe the phænomena of the coloured rings or bands at various angles of incidence.

The first person who investigated the modification of Newton's rings in reference to polarized light was M. Arago, who has given an account of his observations in a beautiful and highly interesting memoir, in the third volume of the Mémoires d'Arcueil, published in 1817. Without knowing what had been done by M. Arago, Professor Airy entered upon the same inquiry in 1831 and 1839 ; but the phænomena which he observed were the same as those which had been previously discovered by M. Arago, with the exception of the modification of the rings when formed by a lens pressed against the surface of a diamond.

When Newton's rings are formed by a lens pressed against

* From the Philosophical Transactions, 1841, part 1. p. 43.

$\uparrow$ These rings may be formed upon almost all transparent bodies with more or less brilliancy, though I have found several substances, and occasionally pieces of glass, that will not absorb the somp. The rings are produced upon natural as well as artificial surfaces, that is, upon transparent surfaces produced by fusion or crystallization, as well as upon those polished by art. The soap being gradually dissolved by the vapour, requires to be frequently renewed. I find that other substances, particularly some of the oils, produce the same effect as soap. The rings disappear quickly by evaporation, and their brilliancy and purity of colour depend on the relative temperature of the vapour and the glass. 


\section{Sir D. Brewster on the Phcenomena of Thin Plates}

a surface of glass, M. Arago observed that they were black centred, as usual; and whether viewed with the eye or with a doubly refracting rhomb of Iceland spar, that the single or the double system of rings had the same colours and the same diameters, the rings being completely polarized at the polarizing angle of the glass.

When the lens, however, was pressed against a metallic mirror, and examined with a doubly refracting rhomboid, two images perfectly similar appeared between a perpendicular incidence, and that of $55^{\circ}$ or the polarizing angle of glass. One of the images disappeared entirely at this angle of $55^{\circ}$, when the principal section of the rhomboid was perpendicular or parallel to the plane of reflexion; but reappeared at greater incidences, with this remarkable peculiarity, that the colour of each of the rings which composed it was complementary to that of the corresponding rings in the image which had disappeared.

M. Arago likewise remarks that we may easily perceive with the eye, naked and without the assistance of any crystal, that at a certain angle near $55^{\circ}$ the rings are composed of two distinct sets having unequal diameters, the rhomboid separating in a great measure the two sets of rings, because they are very unequally polarized. He likewise found that these phænomena were not produced when the rings were formed upon native sulphur and diamond.

"If the presence of a metallic mirror," says M. Arago, "is necessary for the production of the phænomenon in question when the rings are formed upon a plate of air, the case is otherwise when the thin body has much more density, and is in contact by one of its faces with another medium of sufficient refractive power. Thus coal presents often in its cleavages very bright colours, produced by an extremely thin substance, and which are decomposed into two complementary images when they are examined with a rhomboid under sufficiently oblique incidences. The colours which are formed artificially by the progress of evaporation, on thin films of alcohol or oil of sassafias, deposited upon coal or any other analogous substance, give rise also to two images, dissimilar, and of opposite tints*."

In order to investigate the phænomena of the rings of vapour in the iriscope, I illuminated them with light polarized in an azimuth of $90^{\circ}$, or perpendicularly to the plane of incidence, and examined them by a magnifying glass, when the centre of the rings was seen by light reflected at about $53^{\circ} 1 l^{\prime}$,

* Mémoires de Physique et de Chimie de la Société d'Arcueil, tom. iii. p. 363. Paris, 1817. 
the polarizing angle of water. The effect, which was very striking, is shown in Plate II. fig. 1. The central part, AB, of the system of rings, CDEF, was without rings and colours of any kind: the upper half, CD, was part of a system of rings with white circumferences, and was formed by polarized light incident on the film at an angle greater than the polarizing angle of water; while the under half, $\mathrm{EF}$, was part of a system of rings with black circumferences like those seen by common light, and was formed by polarized light incident on the film at an angle less than the polarizing angle of water.

The absence of rings in the middle portion, $\mathrm{AB}$, was of course owing to there being no light reflected from the first surface of the film with which that reflected from the second surface could interfere; and the reason of there being light reflected from the second surface was, that the light reflected from it was not incident at its polarizing angle.

$I$ have elsewhere shown*, that when a film of water is laid upon glass whose refractive index is above 1.508 , there is no angle of incidence upon the first surface of the film which will allow the refracted ray to fall upon the glass at the polarizing angle; and hence at every angle of incidence on the film, the refracted light is reflected from the glass at angles less than the polarizing angle of the united media, or less than an angle whose tangent is equal to $\frac{m}{m}, m$ being the refractive index of the glass, and $m^{\prime}$ that of the water. When the refractive index of the glass is 1.508 , the angle of incidence on the film must be $90^{\circ}$ exactly, in order that the refracted ray may fall upon the glass at the polarizing angle whose tangent is equal to $\frac{m}{m^{*}}$.

Now as the portion of the coloured rings at $C D$, fig. 1 , is formed by the interference of two pencils, CA, DEB, fig. 2, one of which, CA, is reflected at an angle, PCA, above the polarizing angle of water, and the other, $\mathrm{EB}$, at an angle below or less than that angle; while the portion EF, fig. 1, is formed by the interference of two pencils, which are both reflected at angles below or less than that angle, we may suppose that in the formation of the rings with a white circumference, analogous to those with a white centre, there is a loss of half an undulation, while that loss takes place in the interference of common light, or of two pencils reflected on the same side of the polarizing angle.

When the rings are seen at angles between $0^{\circ}$ of incidence and $53^{\circ} 11^{\prime}$, the polarizing angle of water, they are black in

- Philosophical Transactions, 1815, p. 138. 


\section{Sir D. Brewster on the Phanomena of Thin Plates}

the circumference, like the portion shown at EF, fig. 1; and when they are seen at incidences between $53^{\circ} 11^{\prime}$ and $90^{\circ}$, they are white in the circumference, like the portion shown at CD, fig. 1.

If the rings of vapour are formed upon a polished surface of fuor spar, additional phænomena will be exhibited. At all incidences, from $0^{\circ}$ to about $78^{\circ}$, rings of the same character will be seen as already described; but the ratio of the refractive powers of water and fluor spar is such, that at an incidence of $78^{\circ} 4^{\prime}$ upon the surface of the vapour, the light incident on the spar will be reflected at the polarizing angle of the united media. Thus if $m=1.437$, the refractive index of fluor spar, and $m^{\prime}=1 \cdot 336$, the refractive index of water, then $\frac{m}{m^{\prime}}=1 \cdot 0716$, the refractive index of the united media, or of their separating surface. The polarizing angle for this surface will therefore be an angle whose tangent is 1.0756 or $47^{\circ} 5^{t}$, and the angle of incidence on the first surface of the watery film corresponding to the angle of refraction $47^{\circ} 5^{\prime}$, which is the angle of incidence on the second surface, is $78^{\circ} .4$.

At an incidence of $78^{\circ} 4^{\prime}$, therefore, the rings will disappear altogether, as at $53^{\circ} 11^{\prime}$, because the pencil incident on the spar will not be reflected. At incidences greater than $78^{\circ} 4^{\prime}$ the system of rings with the black circumference will again appear as at incidences below $53^{\circ} 11^{\prime}$, and will be visible up to $90^{\circ}$ of incidence, the interfering pencils being now both reflected at angles above the polarizing angle of the surfaces which reflect them.

This experiment with vapour and fluor spar I have not made; and it may be difficult to see the rings at such an oblique incidence. If the rings are formed by soap upon plate glass, or by alcohol upon fluor spar, the second disappearance of the rings may be seen :

$$
\frac{\text { Plate glass }}{\text { soap }} \frac{m}{m^{\prime}}=\frac{1.510}{1 \cdot 487}=1.0154 \text {. }
$$

Polarizing angle at second surface of the soap $45^{\circ} 26^{\prime}$ Angle of incidence on the first surface . . . $71^{\circ} 45^{\prime}$

$$
\frac{\text { Fluor spar }}{\text { alcohol }} \frac{m}{m^{\prime}}=\frac{1 \cdot 437}{1 \cdot 370}=1 \cdot 049 \text {. }
$$

Polarizing angle at second surface of alcohol $46^{\circ} 22^{\prime}$ Angle of incidence on the first surface . . $82^{\circ} 32^{\prime}$

If we call $m, m^{\prime}$ the indices of refraction of the two substances, viz. the film and the surface upon which it rests, $m$ being the larger index, then a ray incident at $90^{\circ}$ will fall 
upon the common surface of the two media at the polarizing angle of that surface, when the angle of refiaction at the first surface is equal to the tangent, or cotangent of the polarizing angle, according as the refractive power of the film is less or greater than that of the body upon which it rests.

Hence we have

and

$$
\sin i^{\prime}=\frac{1}{m} \text { or } \frac{1}{m^{\prime}},
$$

and

$$
\tan i^{\prime}=\frac{m}{m^{\prime}}, \text { or } \cot i^{\prime}=\frac{m}{m^{\prime}},
$$

$$
m=\frac{m^{\prime}}{\sqrt{m^{\prime 2}-1}}, \text { and } m^{\prime}=\frac{m}{\sqrt{m^{2}-1}},
$$

when a ray incident at $90^{\circ}$ is polarized at the second surface, or falls upon it at the polarizing angle.

These formulæ enable us to discover between what limits of refractive power the second disappearance of the rings can take place, and consequently what substances we should employ in order to observe it. In this manner we obtain the following results for the mean rays of the spectrum:-

$\begin{array}{cc}\text { Values of } m^{\prime} . & \text { Values of } \frac{m^{\prime}}{\sqrt{m^{2}-1}} \text {, or } m . \\ 3.000 & 1.061 \\ 2.500 & 1.090 \\ 2.000 & 1.154 \\ 1.900 & 1.176 \\ 1.800 & 1.202 \\ 1.700 & 1.236 \\ 1.600 & 1.281 \\ 1.554 & 1.307 \\ 1.508 & 1.336 \\ 1.500 & 1.341 \\ 1.400 & 1.428 \\ 1.336 & 1.508 \\ 1.307 & 1.554\end{array}$

The limits, therefore, between which the second disappearance of the rings can take place are 1.554, the index for quartz and flint glass, and 1:307, the index for ice. But though the range is very limited, it nevertheless includes a considerable variety of solid and fluid bodies. I have omitted the indices of Tabasheer, and the fluids produced by the compression of gaseous bodies, because, though their refractive powers are beneath 1.307 , they cannot be used in the present inquiry. 


\section{Sir D. Brewster on the Phanomena of Thin Plates}

When $m$ and $m^{\prime}$ are thus related, the rohite-centred rings will just disappear when $i=90^{\circ}$, the light being then incident on the second surface at its polarizing angle. But if we use a film of still less refractive power in relation to the second body, the refracted rays will fall on the second surface at an angle greater than the polarizing angle $\left(i\right.$ being still $90^{\circ}$ ), and consequently the black-centred rings will reappear, and there will be some angle of incidence I on the film, less than $90^{\circ}$, at which the angle of refraction $i^{l}$ will be equal to the polarizing angle of the second surface. This angle will be found from the expression

$$
\sin \mathrm{I}=\frac{m m^{\prime}}{\sqrt{m^{2}+m^{\prime 2}}} .
$$

When $m=m^{\prime}$ no rings whatever will be formed, as no light is reflected at the common surface; but if $m=m^{\prime}$ only for a particular colour in the spectrum of each substance, and if these indices differ considerably for another colour, rings will be formed in which that colour predominates, in which $m>m^{\prime}$, or $m<m^{\prime}$. This takes place in a remarkable manner with oil of cassia and flint glass, in which $m=m^{\prime}$ for the red rays, but $m>m$ for the blue rays. The consequence of this is, that a quantity of blue light is reflected from the separating surface of the oil and the glass; and hence if a sufficiently thin film of oil of cassia is laid upon the glass, blue would greatly predominate in the system of rings.

Hitherto the azimuth of the polarized light has been $90^{\circ}$, or perpendicular to the plane of reflexion. Let us now suppose that its azimuth is gradually changed from $90^{\circ}$ to $0^{\circ}$ by the rotation of the polarizing surface or crystal.

At all azimuths, from $90^{\circ}$ to $0^{\circ}$, the rings with the black circumference are seen, between the angles of $0^{\circ}$ and $53^{\circ} 11$ ', and at the incidence of $53^{\circ} 11^{\prime}$. But at incidences between $53^{\circ} 11^{\prime}$ and $90^{\circ}$, in the case of the iriscope, very interesting phænomena appear. We shall first describe what takes place at $56^{\circ} 45^{\prime}$, the polarizing angle of the black glass. At this angle none of the polarized light is reflected when the azimuth is $90^{\circ}$, and the rings with the rohite circumference are beautifully seen on the dark ground of the glass, which now reflects no light. As the azimuth is changed to $87^{\circ}, 88^{\circ}$, \&c., the black glass reflects a little light, and the two surfaces of the film a little more light, the rings gradually become fainter and fainter, till at an azimuth of about $79^{\circ} 0^{\prime}$ they disappear exactly as they did at $53^{\circ} 11^{\prime}$, and in the azimuth $90^{\circ}$. When this disappearance takes place, the light reflected from the glass seems to be exactly equal to the light reflected from both sur- 
faces of the film. At other angles of incidence the rings disappeared at different azimuths, varying from $90^{\circ}$ to about $45^{\circ}$, as the angle of incidence varied from $53^{\circ} 11^{\prime}$ to $90^{\circ}$. I found it difficult, however, to measure these azimuths with any accuracy, as the rings were not permanent; and I was therefore obliged to form the colours of thin plates upon bighly refracting substances, such as diamond, chromate of lead, artificial realgar, and greenockite (the most refractive of all bodies), which had high polarizing angles. $\Lambda$ solution of fine soap gave brilliant colours when dried, and in this way I obtained the following results with the surface of a very fine diamond. The index of refraction of the soap was $1 \cdot 475$, and that of the diamond $2 \cdot 4.4$, and their respective polarizing angles $55^{\circ} 52^{\prime}$, and $67^{\circ} 43^{\prime}$.

Angle of incidence of the polarized light.

$\begin{array}{ll}55 & 52 \\ 60 & \\ 65 & \\ 67 & 43 \\ 70 & \\ 75 & \end{array}$

Azimuth of the plane of polarization at which Observed. the rings disappear.

$\begin{array}{llll}90 & 0 & 90 & 0 \\ 73 & 0 & 74 & 27 \\ 68 & 30 & 67 & 49 \\ 66 & 20 & 65 & 10 \\ 63 & 30 & 63 & 14 \\ 59 & 15 & 58 & 23 \\ & & 46 & 30\end{array}$

As the disappearance of the rings was not owing to the extinction of one of the interfering pencils, as at $55^{\circ} 52^{\prime}$, for a sufficient quantity of polarized light was reflected from both surfaces of the film, there was reason to believe that it might arise from the two pencils being polarized at right angles to each other, in conformity with the law relating to the action of the second surfaces of plates which $I$ have given in a former paper*.

Calling $x$ the azimuth of primitive polarization, $i$ the angle of incidence on the first surface of the film, $i^{\prime}$ the corresponding angle of refraction, and consequently the angle of incidence on the second surface, $i^{\prime \prime}$ the angle of refraction at the second surface, and

$\phi=$ the inclination of the plane of polarization of the refiected pencil CA, fig. 3,

$\phi^{\prime}=$ that of the refracted pencil CD,

$\phi^{\prime \prime}=$ that of the reflected pencil DE, and

$\phi^{\prime \prime \prime}=$ that of the refracted pencil $\mathrm{EB}$, with which $\mathrm{CA}$ interferes; then by Fresnel's formula we have for the ray $\mathrm{CA}$,

$$
\tan \phi=\tan x \cdot \frac{\cos \left(i+i^{\prime}\right)}{\cos \left(i-i^{\prime}\right)} ;
$$

* Philosophical Transactions, 1830, pp. 148, 149. 
188 Sir D. Brewster on the Phanomena of Thin Plates

and by my formulæ* we have

$$
\begin{aligned}
& \cot \phi^{\prime}=\cot x \cos \left(i-i^{\prime}\right) \\
& \tan \phi^{\prime}=\tan x \cdot \frac{1}{\cos \left(i-i^{\prime}\right)} \\
& \tan \phi^{\prime \prime}=\tan x^{\prime} \cdot \frac{\cos \left(i^{\prime}+i^{\prime \prime}\right)}{\cos \left(i^{\prime}-i^{\prime \prime}\right)} .
\end{aligned}
$$

But, after one refraction,

hence

$$
\tan x^{\prime}=\tan \phi=\tan x \cdot \frac{1}{\cos \left(i-i^{\prime}\right)} ;
$$

and

$$
\tan \phi^{\prime \prime}=\tan x \cdot \frac{1}{\cos \left(i-i^{\prime}\right)} \cdot \frac{\cos \left(i^{\prime}+i^{\prime \prime}\right)}{\cos \left(i^{\prime}-i^{\prime \prime}\right)}
$$

$$
\cot \phi^{\prime \prime}=\frac{1}{\tan x} \cdot \cos \left(i-i^{\prime}\right) \cdot \frac{\cos \left(i^{\prime}-i^{\prime \prime}\right)}{\cos \left(i^{\prime}+i^{\prime \prime}\right)} .
$$

And multiplying this by $\cos \left(i-i^{\prime}\right)$ for the change of plane produced by the second refraction at $E$, we have for the ray EB,

$$
\cot \phi^{\prime \prime \prime}=\cot x \cos ^{2}\left(i-i^{\prime}\right) \cdot \frac{\cos \left(i^{\prime}-i^{\prime \prime}\right)}{\cos \left(i^{\prime}+i^{\prime \prime}\right)}
$$

Now the two pencils which interfere, viz. $C A$ and EB, have their planes of polarization inclined at angles $\phi$ and $\phi^{\prime \prime \prime}$ to the plane of reflexion; but in order that these angles may be complementary to each other, or may together make $90^{\circ}$, we must have $\tan \phi=\cot \phi^{\prime \prime \prime}$, or

$$
\tan x \frac{\cos \left(i+i^{\prime}\right)}{\cos \left(i-i^{\prime}\right)}=\cot x \cos ^{2}\left(i-i^{\prime}\right) \cdot \frac{\cos \left(i^{\prime}-i^{\prime \prime}\right)}{\cos \left(i^{\prime}+i^{\prime \prime}\right)} ;
$$

and consequently

and

$$
\tan ^{2} x=\cos ^{2}\left(i-i^{\prime}\right) \cdot \frac{\cos \left(i-i^{\prime}\right)}{\cos \left(i+i^{\prime}\right)} \cdot \frac{\cos \left(i^{\prime}+i^{\prime \prime}\right)}{\cos \left(i^{\prime}-i^{\prime \prime}\right)}
$$

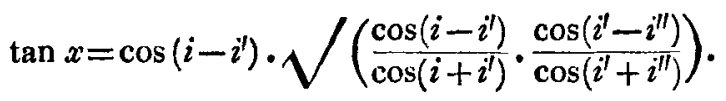

When the angle of incidence is $90^{\circ}, \cos \left(i+i^{\prime}\right)=\sin i^{i}$, and $\cos \left(i-i^{\prime}\right)=\sin i^{\prime}$, and hence

$$
\tan x=\frac{1}{m} \sqrt{\frac{\cos \left(i^{\prime}-i^{\prime \prime}\right)}{\cos \left(i^{\prime}+i^{\prime \prime}\right)}} .
$$

If we now calculate by these formulæ the values of $x$ for the different angles of incidence in the preceding table, and subtract them from $90^{\circ}$, we shall have the numbers in the third

* Philosophical Transactions, 1830. 
column of the table, which agree with those observed within the limits of the errors of observation. In the case of rater and glass, too, where the azimuth of disappearance was observed to be about $79^{\circ}$ or $11^{\circ}$, the formula gives $79^{\circ} 28^{\prime}$, or $10^{\circ} 32^{\prime}$, at an incidence of $56^{\circ} 45^{\prime}$.

In order to ascertain the relation between the mutual inclination of the planes of polarization of the interfering pencils when they produced black-centred or white-centred rings, I have computed the following table for an incidence of $56^{\circ} 4.5^{\prime}$.

Azimuth of polarized

\begin{tabular}{|c|c|c|c|c|}
\hline light. & + & & -4 & \\
\hline $9 \stackrel{\circ}{9}$ & $90^{\circ}$ & ó & $90^{\circ}$ & \\
\hline 8730 & 74 & 43 & 82 & \\
\hline 850 & 49 & 30 & 75 & \\
\hline $79 \quad 28$ & 28 & 26 & 61 & \\
\hline 70 & 15 & 28 & 43 & \\
\hline 45 & 5 & 4.5 & 18 & \\
\hline 35 & 4 & 3 & 13 & \\
\hline 20 & 2 & 6 & 7 & \\
\hline 0 & 0 & 0 & 0 & \\
\hline
\end{tabular}

Film of water and glass.

Inclination of planes $\varphi$ and $\varphi^{\prime \prime \prime}$.

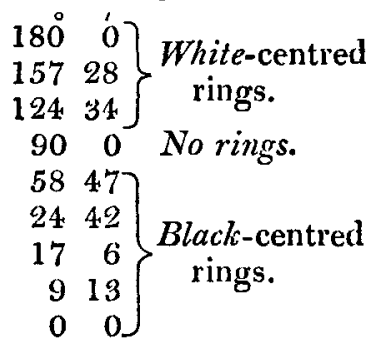

By taking $\varphi$ positive, or on the right-hand side of the plane of reflexion, then $\varphi^{\prime \prime \prime}$ must be negative, or on the left-hand side of that plane*; hence $+\phi,-\phi^{\prime \prime \prime}$ will be the mutual inclinations of the planes of polarization of the interfering pencils, and we obtain the important law,

That when tro polarized pencils reflected from the surfaces of a thin plate lying on a reflecting surface of a different refractive porver interfere, half an undulation is not lost, and w $\mathbf{\text { HTE- }}$ centred rings are produced, provided the mutual inclination of their planes of polarization is greater than $90^{\circ}$; and that rohen this inclination is less than $90^{\circ}$, half an undulation is lost, and BLACK-centred rings are produced; when the inclination is exactly $90^{\circ}$, the pencils do not interfere, and no rings are produced.

At an incidence of $45^{\circ}$ upon water and glass, where the signs of $\varphi$ and $\phi^{\prime \prime \prime}$ are the same, the maximum difference in the planes of polarization is $23^{\circ} 12^{\prime}$, which takes place in azimuth $70^{\circ} 30^{\prime}$; and at an incidence of $10^{\circ}$ the greatest difference is $2^{\circ} 16^{\prime}$, which takes place at an azimuth of about $45^{\circ}$.

In the case of soap and plate glass, where the black-centred rings appear beyond the incidence of $71^{\circ} 45^{\prime}$, the difference of inclination in the planes of the two pencils is also less than $90^{\circ}$.

1 was now desirous of examining the phænomena of a per-

* See Philosophical Transactions, 1830, p. 70, fig. 1. 


\section{Sir D. Brewster on the Phanomena of Thin Plates}

fect system of rings when the film had a greater refractive power than the substance upon which it was laid; after many ineffectual attempts to obtain such a system, I succeeded by laying a very small portion of oil of laurel upon roater placed in a black vessel, or on the surface of diluted or real ink. The rings thus produced are splendid beyond description, and exhibit the various phænomena with singular beauty. As the polarizing angle of the oil exceeds that of the water, the blackcentred rings are seen at the polarizing angle of the water, when the reflected light disappears. They continue to be seen till we reach the polarizing angle of the oil, when the rings disappear, and the white-centred ones commence, and continue till we reach the incidence of $90^{\circ}$.

In forming thin films upon metallic surfaces, I employed many of the metals, and found the phrenomena nearly the same upon them all, and differing very little from those produced upon transparent bodies. On a fine specimen of specular iron ore, I found a system of rings ready-formed, with three orders of colours. The azimuth of the polarized light being inclined $90^{\circ}$ to the plane of reflexion, the system of rings disappeared wholly at an angle of incidence of $58^{\circ} 36^{\prime}$, which is therefore the polarizing angle of the unknown substance of which it was formed: consequently its index of refraction is about $1 \cdot 638$. Between this angle and $90^{\circ}$ of incidence, the white centred rings appeared; but at $72^{3} 39^{\prime}$, the polarizing angle of the iron (which gives its refractive power for the red rays 3.200), the rings were singularly fine, being seen on a beautiful blue ground, produced by the disappearance of the red light, which is polarized at that angle. I now measured the azimuth of the plane of polarization when the rings disappeared, which was $59^{\circ} 25^{\prime}$, whereas by the formula it is $57^{\circ} 59^{\prime}$; a discrepancy not to be wondered at, when we consider that the index of refraction for the red rays, viz. $3 \cdot 200$, was used, in place of that for the mean ray, which is not known. The inclination of the planes of polarization of the two interfering pencils, when calculated by the previous formulæ, is $+32^{\circ} 7^{\prime}$, and $-57^{\circ} 53^{\prime}$; so that these planes being

* These thin plates of oil of laurel exhibit some curious phænomena, which I believe have not been noticed. If we wet with water, alcohol, or the oil of laurel itself, the extremity of a short piece of wire, such as a large pin, and hold the pin in the hand, so that its head may be above, and almost touching the film, the film will recede in little waves of a circular shape, which form a new system of coloured rings; and they become covered with the vapour from the fluid on the head of the pin in such small particles that they reflect no light, and the rings appear to be blackened. By withdrawing the pin, the film is restored to its former state. The same effect is produced by heating the pin, or the fluid upon it, to promote evaporation. 
inclined $90^{\circ}$ to each other, as in the case of soap and diamond, no interference takes place, and the rings disappear.

In the fine specimens of oligist iron ore from Elba, I have found crystals covered with the most beautiful coloured films, both of uniform and variable thickness. These films are not acted upon by the ordinary acids, like the coloured films upon steel, and appear, from their optical properties, to be of a metallic nature. When they are exposed to a polarized ray, they exhibit generally the same phænomena as the films already described; but there is no angle of incidence at which the colours disappear, either in the azimuth of $90^{\circ}$, at the polarizing angle of the first surface of the film, or in those azimuths where the pencils, from the first and second surface, have their planes of polarization inclined $90^{\circ}$ to each other. This, no doubt, arises from the high dispersive power of the film, in consequence of which the different homogeneous rays are polarized at angles considerably different from each other.

'The phænomena of transparent films of low refractive power, when laid upon the polished surfaces of metals, and exposed to polarized light, are not very different from those which are exhibited when the film rests upon a transparent surface. I at first used a solution of soap, which produced pretty good tints on speculum metal; but at last I fell upon a method of laying down the most beautiful systems of coloured rings upon all surfaces of all forms, whether metallic, transparent or opake. For this purpose I used the oil of laurel, which, when placed upon the surface of water, expands into a film, which gives the finest system of coloured rings. Having laid the plate of polished metal in a small porous wooden tray, such as is used for holding minerals, I poured water into it, so as to cover the metallic surface to the depth of the fiftieth part of an inch. I then formed a film of the oil upon the water, immediately above the metallic surface. In a short time the absorption of the water by the porons tray allowed the film of oil to descend and rest upon the metallic surfuce*. When the adhering moisture was removed by evaporation, the film was extremely beantiful; and if protected from dust may be preserved for any length of time.

Having laid a film of this kind upon speculum melal, I obtained the following results. The coloured rings disappeared almost completely at $56^{\circ}$, the polarizing angle of the oil. The black-centred rings appeared at all angles less than $56^{\circ}$, and the rehite-centred rings at all angles above it. Both the systems of rings were exceedingly distinct at the greatest angles

* The same effect is produced more slowly by evaporation; or the water may be sucked out of the tray by a tube, or run off by an aperture. 


\section{Sir D. Brewster on the Phanomena of Thin Plates}

of incidence, whereas on transparent surfaces of low refractive power, they can scarcely be seen at such angles. When the azimuth of the polarized ray varies from $90^{\circ}$ to $0^{\circ}$, the rings disappear at different angles of incidence; or when the angles of incidence vary, the rings disappear in different azimuths. I measured these azimuths when the polarized ray was incident upon speculum metal, and obtained the following numbers :-

\begin{tabular}{|c|c|c|c|}
\hline Angles of incidence & $\begin{array}{l}\text { Azimuth in wh } \\
\text { Observed }\end{array}$ & rings disappear. & \\
\hline $90 \quad 0$ & , & $4.0 \quad 23$ & Difference. \\
\hline 7150 & 5625 & $57 \quad 22$ & -057 \\
\hline $\begin{array}{ll}60 & 0\end{array}$ & $65 \cdot 45$ & 654 & +04.1 \\
\hline 56 & 900 & 90 & \\
\hline
\end{tabular}

In computing column third from the formula in p. 188, I used 1.49 as the index of refraction of oil of laurel, and 4.011 as the index of refraction for speculum metal, as deduced from my experiments on its elliptic polarization*.

I have made similar experiments when the rings were transferred to silver, whose elliptical polarization approaches nearest to circular polarization ; and to grain tin, which appears to have the highest refractive power of any of the metals; but I found it very difficult to ascertain with any accuracy the azimuths in which the rings disappear.

If we use common in place of polarized light in the preceding experiments, and analyse the reflected light by a rhomb of calcareous spar, the very same phænomena will be exhibited.

When the films or thin plates are not laid upon the surfaces of fluid or solid bodies, the phænomena are of an entirely different kind. At all angles of incidence, and in all azimuths, the colours and character of the rings are the same, whether we use common or polarized light. In obtaining this result I stretched thin films of various oils, such as oil of laurel, oil of cassia, oil of turpentine, and many others, across circular apertures, and examined them in light polarized in different azimuths. The rings of course vanished at the polarizing angle of the oil, and the brilliancy of the colours varied with the angles of azimuth and incidence, but the complementary rings never appeared, the rings being always those with the black centret.

* Philosophical Transactions, 1830,p. 324.

+ 'The physical phænomena exhibited in these attenuated films are very remarkable. A current of fluid is projected from the margin and centre of the ring of fluid across the fluid surface, resembling the top of a pine apple. This movement makes the film thinner at some places than others, and 
In order to understand the cause of this, we must inquire into the state of polarization of the interfering pencils. The ratio of refraction being the same at both surfaces of the film, we have

$$
\tan \phi=\tan x \cdot \frac{\cos \left(i+i^{\prime}\right)}{\cos \left(i-i^{\prime}\right)} \text {, and } \cot \phi^{\prime \prime \prime}=\cot x \cdot \frac{\cos ^{3}\left(i-i^{\prime}\right)}{\cos \left(i+i^{\prime}\right)} \text {; }
$$

and when $\tan \phi=\cot \phi^{\prime \prime \prime}$, which is the case when $\phi+\phi^{\prime \prime \prime}=90^{\circ}$, we have

$$
\tan x=\frac{\cos ^{2}\left(i-i^{\prime}\right)}{\cos \left(i+i^{\prime}\right)}
$$

When $i=90^{\circ}, \tan \varphi=\mathrm{A}$, or the azimuth of the polarized ray, and $\cot \phi^{\prime \prime \prime}=\frac{\cos ^{3} i^{\prime}}{\sin i^{\prime}}$.

If we now compute the values of $\phi$ and $\phi^{\prime \prime \prime}$ at different angles of incidence and in different azimuths of the polarized light, we shall obtain the results in the following Table. In azimuths

\begin{tabular}{|c|c|c|c|c|c|c|c|c|}
\hline \multirow[b]{3}{*}{$\begin{array}{l}\text { Angles of } \\
\text { incidence. }\end{array}$} & \multicolumn{8}{|c|}{ Inclination of the planes of polarization of the two pencils, $\varphi$ and $\varphi^{\prime \prime \prime}$. } \\
\hline & \multicolumn{2}{|c|}{ Azimuth $22^{\circ} 30^{\prime}$. } & \multicolumn{2}{|c|}{ Azimuth $45^{\circ}$. } & \multicolumn{2}{|c|}{ Azimuth $67^{\circ} 30^{\prime}$. } & \multicolumn{2}{|c|}{ Azimuth $80^{\circ}$. } \\
\hline & 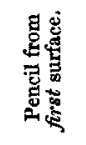 & 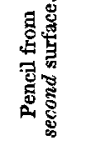 & 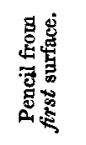 & 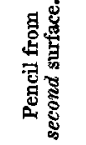 & 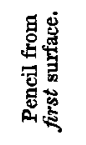 & 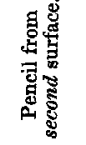 & 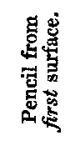 & 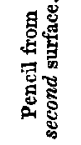 \\
\hline 0 & 220 & 2230 & $45^{\circ} 0$ & $45^{\circ} \theta^{\prime}$ & 670 3ó & 670 3ó & 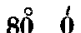 & 8006 \\
\hline 10 & 2142 & 225 & 4351 & 4424 & 6640 & 674 & 7936 & 7948 \\
\hline 20 & 1911 & 1934 & 4013 & 4038 & 6413 & 64. 14 & 7813 & 7823 \\
\hline 30 & 1525 & 1555 & 3340 & 3433 & 587 & 5858 & 7510 & 7538 \\
\hline 40 & 1018 & 111 & 2341 & 2511 & 4321 & 4837 & 686 & 686 \\
\hline 50 & 418 & 452 & 1018 & 1137 & 2341 & 2624 & $\begin{array}{ll}45 & 52\end{array}$ & 4923 \\
\hline 56 in 45 & $\begin{array}{ll}0 & 0\end{array}$ & & $\begin{array}{ll}0 & 0\end{array}$ & $\begin{array}{ll}0 & 0\end{array}$ & $\begin{array}{ll}0 & 0\end{array}$ & & & $\begin{array}{ll}0 & 0\end{array}$ \\
\hline 60 & 26 & $2 \mathbf{3 5}$ & $\mathbf{5}$ & 613 & 125 & 1444 & 2642 & 3142 \\
\hline 70 & 754 & 1152 & 1832 & 2653 & $\begin{array}{ll}39 & 0\end{array}$ & 5045 & $62 \quad 16$ & $\begin{array}{ll}70 & 49\end{array}$ \\
\hline 80 & 1511 & 2441 & 3313 & 4758 & 5741 & 6932 & 7456 & 8058 \\
\hline 85 & 1840 & 3334 & $\begin{array}{ll}39 & 12\end{array}$ & $\begin{array}{ll}58 & 2\end{array}$ & 635 & $75 \quad 30$ & 7748 & 8343 \\
\hline 90 & 2230 & 4357 & 450 & $66 \quad 44$ & 6730 & 7954 & 800 & 8540 \\
\hline
\end{tabular}
$0^{\circ}$ and $90^{\circ}, \phi$ and $\phi^{\prime \prime \prime}=0$.

The results in this Table, which may be considered as those of

hence arises an irregular system of coloured bands, with an incessant play of varying tints, as if the fluid were animated. The bands of colour are serrated with salient points, from which the fluid seems to shoot across the film. In the oils of cinnamon, naphtha, spearmint, wormwood, rapeseed, nutmegs, bergamot, savine, rosemary, \&c., the phænomena are peculiarly beantiful. With poppy oil, the red and green tints of the 4 th, 5 th, and 6 th orders were also seen.

Phil. Mag. S. 8. Vol. 32. No. 214. March 184.8. 


\section{Sir D. Brewster on the Phanomena of Thin Plates}

observation*, exhibit at one glance the general phænomena at all angles of incidence and azimuth.

The two interfering pencils are in every case reflected at angles either both above or both below the polarizing angle, and hence their planes of polarization are always on the same side of the plane of reflexion and in the same quadrant, and consequently they never can be at right angles to each other so as to prevent interference. For the same reason the inclination of the planes never can exceed $90^{\circ}$, so as to produce the complementary white-centred rings, in conformity with the law previously given.

If, for example, we compute the value of $x$ in the preceding formula at an incidence of $70^{\circ}$, we shall find it $66^{\circ} 25^{\prime}$, at which azimuth the inclinations $\phi$ and $\varphi^{\prime \prime \prime}$ of the planes of polarization are $40^{\circ} 47^{\prime}$, and $49^{\circ} 53^{\prime}$; but though the sum of these angles is $90^{\circ}$, yet the real inclination of the planes is $\phi^{\prime \prime \prime}-\phi$ $=9^{\circ} 6^{\prime}$.

This property of parallel transparent films, of giving by reflexion pencils polarized in planes at various inclinations, when the incident light is polarized in different azimuths, enables us to obtain two pencils of polarized light, inclined at any angle, varying from $0^{\circ}$ to $21^{\circ} 44^{\prime}$ in glass, and to study the phænomena which such pencils exhibit, either in their mutual action, or in their relations to other properties of light.

But the phsenomena become more varied and interesting when the second surface of the plate is inclined to the first. In this way we may produce effects analogous to those produced by a change in the refractive power of the second surface by contact with another refracting surface, and obtain pencils inclined $90^{\circ}$ to each other, and therefore exhibiting the white-centred rings. The phænomena will in this case resemble those of a film of oil upon water.

When the refractive index of a parallel film exceeds $1 \cdot 508$, the ray is incident on the second surface at an angle less than the polarizing angle; but by inclining the second surface we can make it fall upon it at a greater angle than the polarizing angle. The phænomena may be still more varied by inclining the surface of emergence to the surface of incidence $\dagger$; but as it is not easy to obtain films with faces suitably inclined to each other, it is unnecessary to pursue this branch of the subject any further.

Such are the phænomena of thin and thick plates when viewed by polarized light, or by common light subsequently analysed by a doubly refracting rhomb. But if we use polar-

* See Philosophical Transactions, 1830, pp. 74, 138.

+ Ibid. p. 147, fig. 3. 
ized light, and subsequently analyse the light transmitted through the thin plates, we shall obtain a series of very interesting and instructive phænomena, analogous to those produced by plates of doubly refracting crystals which exhibit the polarized tints. In both these cases, the film is interposed between a polarizing plate and an analysing rhomb. If the film is too thick to produce colours, it will depularize the polarized ray, in a manner analogous to that of a crystallized plate, which is not thin enough to give the polarized tints; and if the film is sufficiently thin to produce uniform tints, a coloured band or system of rings, with black or white centres. Their action is analogons to that of thin crystallized plates, which either produce uniform tints like the laminze of sulphate of lime, or uniaxal or biaxal systems of rings.

It would be unprofitable to describe minutely the great variety of phænomena which thin plates thus exhibit, as they vary with the refractive power of the fluid or solid upon which they are laid, so that $I$ shall confine myself to the case in which a thin plate of oil of laurel rests on the surface of a specimen of artificial realgar. In common light, the colours of this film are very beautiful, but when examined in polarized light by an analysing rhomb, they are brilliant beyond description.

1. When the azimuth of the polarized light is $90^{\circ}$, and the incidence of the polarized ray $56^{\circ} 5^{\prime}$, the polarizing angle of oil of laurel.

When the film is viewed without the polarizing rhomb, no rings are seen, as there is no light reflected from the first surface of the film, and consequently no interference.

When the film is viewed with the polarizing rhomb, having its principal section in the plane of incidence, no rings appear, either in its ordinary or extraordinary image. But if the plane of polarization is less or more than $90^{\circ}$, by even a small quantity, then after the rhomb has been turned round nearly $90^{\circ}$ towards the right, a system of black-centred rings is seen for an instant, and these, after disappearing, are followed by a system of white-centred ones, the white-centred rings appearing first if the rhomb is turned to the left. The same phænomena are repeated in every quadrant of the circular motion of the rhomb.

2. When the azimuth of the polarized light varies from $90^{\circ}$ to $0^{\circ}$, the incidence, being $56^{\circ} 5^{\prime}$, as before.

At $90^{\circ}$ azimuth the phænomena are as above described.

At $67 \frac{1}{2}^{\circ}$. Rhomb $0^{\circ}$, no rings.

Rhomb turning to the right, the white-centred rings appear, then vanish, when the azimuth of the rhomb is less than $67 \frac{1}{2}^{\circ}$; then black-centred rings appear, which vanish at $180^{\circ}$; then 
succeed the white-centred ones, which vanish at about $210^{\circ}$; then the black-centred, which continue to $360^{\circ}$.

At $45^{\circ}, 22 \frac{1}{2}^{\circ}$. The very same phænomena appear at these and other azimuths, the azimuths of the rhomb at which the rings disappear out of the plane of incidence being a little less than the azimuths of the polarized light.

At $0^{\circ}$. The evanescence of the rings takes place when the azimuths of the rhomb are $0^{\circ}, 90^{\circ}, 180^{\circ}$, and $270^{\circ}$, the rohitecentred rings appearing in the first and third, and the blackcentred ones in the second and fourth quadrant.

3. Azimuth of polarized light $90^{\circ}$.

Incidence of polarized light $68^{\circ} 3^{\prime}$, the polarizing angle of realgar.

At this angle all the light reflected from the realgar has disappeared, excepting a dark bluish purple, in the middle of which is seen, without using the rhomb, a splendid system of richly-coloured rings, with a white centre. When the rhomb is applied as before, and performs a complete revolution, the white-centred rings are seen all round, disappearing at $90^{\circ}$ and $270^{\circ}$.

4. When the azimuth of the polarized light varies from $90^{\circ}$ to $0^{\circ}$, the incidence being $68^{\circ} 3^{\prime}$, as before.

At $90^{\circ}$ azimuth, the phænomena are as above described.

At $80^{\circ}$, and all other azimuths, the rohite-centred rings are seen when the rhomb is at $0^{\circ}$; but they disappear at azimuths of the rhomb a little less than the azimuths of polarization, and are then succeeded by the black-centred rings.

At $0^{\circ}$ azimuth, the rings disappear when the rhomb is at $0^{\circ}$ and $180^{\circ}$, and are black-certred all round.

Without using the rhomb, the rings always disappear at the azimuth $x$, at which the planes of polarization of the interfering pencils are rectangular.

At incidences above $68^{\circ} 3^{\prime}$, the phænomena are of the same character. The rings are white-centred in $90^{\circ}$ of azimuth, and when the rhomb is at $0^{\circ}$. They become very brilliant about $45^{\circ}$. Near $90^{\circ}$ of rotation the rings vanish, and immediately the black-centred system appears, which quickly vanishes, and is succeeded by the white-centred system.

5. Angles of incidence less than $56^{\circ} 5^{i}$.

In $90^{\circ}$ of azimuth of the polarized ray, and the rhomb being at $0^{\circ}$, the black-centred rings are seen, and continue to be seen during a complete revolution of the rhomb. In all azimuths, from $90^{\circ}$ to $0^{\circ}$, the rings disappear by turning the rhomb to the left, the arch diminishing from $90^{\circ}$ to $0^{\circ}$; but in azimuths of an intermediate magnitude, the disappearance of the rings is followed by the appearance of the rohile-centred 
system, which quickly disappears, and is succeeded by the black-centred system. This phænomenon is seen best near $45^{\circ}$ of azimuth.

When the plates or films are too thick to give the coloured rings, the phænomena of the differently polarized pencils may be finely seen by using coloured glasses, in which the pencils reflected from both surfaces may be observed. If the glass is green, for example, the pencil or image of a small aperture or luminous body will be green, while that reflected from the first surface, though in reality colourless, will appear red, from the physiological action of the green light upon the retina. Hence the two differently polarized pencils will have different colours, as if they were the tints of polarized light. If these coloured glasses are laid upon, or cemented on one side to, metals or highly refracting substances, the polarization of the coloured pencils which they reflect will be modified according to the principles already explained, and they will exhibit many interesting phænomena, varying with the colours of the glasses, as if the colours were produced by the absorption of polarized light.

In order to convey a general idea of the different classes of phænomena described in the preceding paper, I have represented two of the most important in figs. 4 and 5.

1. Glass and Water.-When a film of aqueous vapour is laid upon glass whose index of refraction is 1.508 , the rings disappear at $53^{\circ} 11^{\prime}$, the polarizing angle of the water, and also in the various azimuths where the two interfering pencils are polarized in planes at right angles to each other. At all azimuths greater than these, and at angles of incidence above the polarizing angle, the white-centred rings appear; and at all azimuths less than these, and at all incidences (except those at which the white-centred rings are seen), the black-centred rings appear.

The following Table shows the values of $x$, or the azimuths of disappearance of the rings, as computed from the formula in p. 49 :-

\begin{tabular}{|c|c|c|}
\hline Angles of incidence. & Azimuths. & Complements. \\
\hline 53 1' & 900 & 0 \\
\hline 550 & 82 & 752 \\
\hline 60 & 7652 & 138 \\
\hline 65 & $75 \quad 15$ & 1445 \\
\hline 67 & $75 \quad 10$ & 1450 \\
\hline 70 & 7530 & 14. 30 \\
\hline 73 & $76 \quad 18$ & 1342 \\
\hline 74 & 7642 & 1318 \\
\hline
\end{tabular}


198 Sir D. Brewster on the Phonomena of Thin Plates.

\begin{tabular}{|c|c|c|}
\hline Angles of incidence. & Azimuths. & Complements \\
\hline $7 \stackrel{\circ}{5}$ & $7 \stackrel{\circ}{9} 9$ & $1 \stackrel{\circ}{2} 1^{\prime}$ \\
\hline 76 & $77 \quad 36$ & 1224 \\
\hline 80 & $80 \quad 0$ & 100 \\
\hline 85 & $84 \quad 15$ & 545 \\
\hline 90 & $90 \quad 0$ & 0 \\
\hline
\end{tabular}

If we now conceive $A B$, fig. 3 , to be the section of the plane of incidence, having the different incidences marked upon it from $90^{\circ}$ to $53^{\circ} 11^{\prime}$, and if round a centre in $\mathrm{AB}$ prolonged, where $0^{\circ}$ of incidence falls, we describe the azimuthal circle ZAZ, then the complements of the azimuths of the polarized light being set off from the corresponding angles of incidence on each side of $A B$, the curves $A C B, A C B$ passing through these points will show at what angles of incidence and azimuth the rings disappear, in consequence of the planes of polarization of the two pencils being at these places rectangular

At all incidences, and in all azimuths within the shaded space $A C B C$, the white-centred rings are seen, and at all other azimuths and incidences the black-centred rings are seen.

2. Fluor Spar and Watcr.-I have taken this combination as a specimen of the phænomena which take place at some incidences less than $90^{\circ}$, when the refracted ray falls on the second surface of the film, at angles greater than its polarizing angle. The following Table shows the values of $x$ and their coinplements :-

\begin{tabular}{|c|c|c|c|}
\hline Angles of incidence. & Azimuths. & Compl & lements \\
\hline $5 \stackrel{\circ}{3} 1^{1}$ & $\stackrel{0}{0} 0$ & & \\
\hline 55 & 8235 & 7 & 25 \\
\hline 60 & 7747 & 12 & 13 \\
\hline 63 & 7654 & 13 & 6 \\
\hline 65 & 7641 & 13 & 19 \\
\hline 67 & 776 & 12 & 54 \\
\hline 70 & 789 & 11 & 51 \\
\hline 75 & 820 & 8 & 0 \\
\hline 78 & 8841 & 11 & 9 \\
\hline 78 & 900 & 0 & 0 \\
\hline 80 & 8328 & 6 & 32 \\
\hline 85 & 7731 & 12 & 29 \\
\hline 90 & 7414 & 15 & 46 \\
\hline
\end{tabular}

By projecting these values, as is done in fig. 4, we obtain a double set of curves which unite at $D$, where the angle of incidence is $78^{\circ} 4^{\prime}$, at which the refracted ray falls upon the second surface at its polarizing angle. 
At all incidences, and in all azimnths within the shaded portions of the figure $\mathrm{ZAZD}, \mathrm{DCBC}$, the white-centred rings are seen. At all azimuths and incidences corresponding with the outlines of the curves $\mathrm{ZDZ}, \mathrm{DCBC}$, the rings disappear; and at all azimuths and incidences without the shaded portions of the figure, the black-centred rings are seen*.

St. Leonard's College, St. Andrews, April 8, 1841.

XXX. Photographic phanomena referring to the various Actions of the red and yellow Rays on Daguerreotype Plates when they have been affected by daylight. By A. Crauder, Esq.

To the Editors of the Philosophical Magazine and Journal.

Gentlemen,

HAVING made on the 24th of October 1847, a communication to the Académie des Sciences of Paris similar to that I sent on the 10th of June to the Royal Society, On different Properties of Solar Radiation acting on Silver Plates coated with Iodine, or its compounds with Bromine or Chlorine, a discussion ensued, in which Messrs. Ed. Becquerel and Gaudin (see Comptes Rendus, Oct. 91 and Nov. 2) controverted the accuracy of some part of my experiments. I had stated that the red and yellow glasses had the property, as well as the pure red and yellow rays of the spectrum, of destroying the photogenic action produced by daylight on silver plates coated with iodine, or its compounds with bromine and chlorine; Messrs. Ed. Becquerel and Gaudin asserted that the red and yellow glasses had not the property of destroying, but of continuing the action commenced by daylight on the simply iodized plate.

As soon as I was apprised of the remarks made by Messrs. Becquerel and Gaudin, I repeated the experiments, and to my great surprise I found that the destructive action of the red and yellow glasses did not appear, on this trial, to extend to the simply iodized, but only to the bromo-iodized plate. I lost no time in communicating to the Académie des Sciences the result of these experiments; and at the meeting of the 22nd of November my letter stating the apparent contradiction was read.

This led me to continue the experiment, in order to examine the question more attentively, and fortunately enabled me to discover some new properties so interesting that I made

* No reference is made in these figures to the phænomena which are seen by using both polarized light and the analysing rhomb. 